\title{
ANALISIS POTENSI SEKTOR UNGGULAN DAN PERUBAHAN STRUKTUR EKONOMI DI KABUPATEN SERANG PROVINSI BANTEN
}

\section{ANALYSIS OF POTENTIAL LEADING SECTORS AND CHANGES IN ECONOMIC STRUCTURE IN SERANG REGENCY OF BANTEN PROVINCE}

\author{
Faujatul Hasanah*, Iwan Setiawan, Trisna Insan Noor, Eka Purna Yudha \\ Fakultas Pertanian, Universitas Padjadjaran \\ *E-mail: faujatulhasanah@gmail.com \\ (Diterima 20-1-2021; Disetujui 27-1-2021)
}

\begin{abstract}
ABSTRAK
Pembangunan ekonomi merupakan bagian dari upaya meningkatkan kesejahteraan. Laju pembangunan ekonomi dalam suatu daerah ditunjukkan dengan semakin meningkatnya pertambahan PDRB. Tujuan penelitian ini adalah untuk mengidentifikasi sektor-sektor unggulan dan menganalisis pergeseran struktur ekonomi di Kabupaten Serang periode 2015-2019. Alat analisis yang digunakan yaitu analisis Location Quotient (LQ) dan Shift Share (SS). Data yang digunakan adalah data sekunder yang diperoleh dari Badan Pusat Statistik Kabupaten Serang. Hasil penelitian menunjukkan ada empat sektor yang memiliki menjadi sektor unggulan di Kabupaten Serang, yaitu sektor pertanian, kehutanan, dan perikanan; sektor industri pengolahan; sektor administrasi pemerintahan, pertahanan, dan jaminan sosial wajib; serta sektor jasa pendidikan. Sektor pertanian, kehutanan, dan perikanan merupakan sektor unggulan di Kabupaten Serang dengan angka LQ paling besar yaitu 1,56, namun analisis shift share menunjukan bahwa sektor ini memiliki pertumbuhan yang lambat dan daya saing yang rendah. Sektor industri pengolahan juga memiliki pertumbuhan yang lambat, namun sektor ini merupakan sektor unggulan dan memiliki daya saing yang tinggi. Struktur perekonomian di Kabupaten Serang telah mengalami pergeseran menuju sektor tersier, hal tersebut ditandai dengan persentase kontribusi sektor tersier yang meningkat, sedangkan sektor sekunder dan primer mengalami penurunan.
\end{abstract}

Kata kunci: struktur ekonomi, pdrb, sektor basis, location quotient, shift share

\begin{abstract}
Economic development is part of efforts to improve welfare. The rate of economic development in a region is indicated by the increasing GDP growth. The purpose of this research is to identify leading sectors and analyze the shift in economic structure in Serang Regency in the period 20152019. The analysis tools used are Location Quotient (LQ) and Shift Share (SS) analysis. The data used is secondary data obtained from the Central Statistics Agency of Serang Regency. The results showed that there are four sectors that have become the leading sectors in Serang Regency, namely agriculture, forestry, and fisheries; processing industry sector; government administration, defense, and social security sectors are mandatory; as well as the education services sector. Agriculture, forestry, and fisheries sector is the leading sector in Serang Regency with the largest $L Q$ number of 1.56, but shift share analysis shows that this sector has slow growth and low competitiveness. The processing industry sector also has slow growth, but it is a leading sector and has high competitiveness. The structure of the economy in Serang regency has shifted towards the tertiary sector, it is characterized by an increasing percentage of tertiary sector contribution, while the secondary and primary sectors have decreased
\end{abstract}

Keywords: economic structure, gdp, sector base, location quotient, shift share 


\section{PENDAHULUAN}

Pembangunan ekonomi daerah adalah suatu proses dimana pemerintah daerah dan masyarakatnya mengelola sumberdaya yang ada dan membentuk suatu pola kemitraan antara pemerintah daerah dan swasta untuk menciptakan suatu lapangan kerja baru dan merangsang perkembangan kegiatan ekonomi di wilayah tersebut. Pembangunan ekonomi daerah merupakan suatu proses yang mencakup pembentukan institusi-institusi baru, pembangunan industri-industri alternatif, perbaikan kapasitas tenaga kerja yang ada untuk menghasilkan produk dan jasa yang lebih baik, identifikasi pasar-pasar baru, alih ilmu pengetahuan dan pengembangan perusahaan-perusahaan (Arsyad, 2010)

Subandi (2014) mengungkapkan bahwa beberapa ekonom memberikan pengertian istilah pembangunan ekonomi sebagai peningkatan pendapatan perkapita masyarakat yaitu tingkat pertambahan GDP/GNP (Gross Domestic Product/Gross National Product) pada suatu tahun tertentu melebihi tingkat pertambahan penduduk, atau perkembangan GDP/GNP yang terjadi dalam suatu negara dibarengi oleh perombakan dan modernisasi struktur ekonominya.

Struktur ekonomi secara sederhana dapat diartikan sebagai peran atau seumbangan sektor-sektor dalam perekonomian Indonesia Terhadap Produk Domestik Bruto (PDB) Indonesia. Menurut Eka Nurdiano, struktur ekonomi dapat diartikan sebagai komposisi peranan masing-masing sektor dalam perekonomian baik menurut lapangan usaha maupun pembagian sectoral ke dalam sektor primer, sekunder dan tersier (Faried \& Sembiring, 2019)

Struktur ekonomi suatu daerah secara kuantitatif bisa digambarkan dengan besarnya distribusi persentase nilai tambah bruto dari masing-masing sektor terhadap nilai total PDRB. Distribusi persentase PDRB secara sektoral menunjukkan peranan masingmasing sektor terhadap perekonomian secara keseluruhan. Semakin besar persentase suatu sektor, semakin besar pula pengaruh sektor tersebut di dalam perkembangan ekonomi suatu daerah. Oleh karena itu, pemerintah daerah berusaha untuk meningkatkan dan mengembangkan sektor-sektor yang memiliki potensi sektor unggulan yang berpengaruh signifikan terhadap Produk Domestik Regional Bruto (PDRB). Hal 
ini juga dilakukan oleh pemerintah Kabupaten Serang. Kabupaten Serang merupakan salah satu kabupaten yang terletak di Provinsi Banten, memiliki luas wilayah $1.734,28 \mathrm{~km} 2$ atau $17,95 \%$ dari luas wilayah Provinsi Banten.

Produk Domestik Regional Bruto (PDRB) merupakan indikator perekonomian yang sangat dibutuhkan oleh pemerintah sebagai bahan pertimbangan pembuatan kebijakan yang sangat mendukung perekonomian Kabupaten Serang. Sumbangsi dari tiap sektor Produk Domestik Regional Bruto (PDRB) Kabupaten Serang mengalami perubahan ditiap tahunnya karena dipengaruhi oleh berbagai faktor. Salah satu dampak dari keadaan ini adalah terjadinya perubahan struktur perekonomian di Kabupaten Serang di tiap tahunnya. Seperti yang dintayakan oleh Todaro et al (2011) bahwa proses perubahan struktur perekonomian ditandai dengan: menurunnya pangsa sektor primer (pertanian), meningkatnya pangsa sektor sekunder (industri), dan pangsa sektor tersier (jasa) juga memberikan kontribusi yang meningkat sejalan dengan pertumbuhan ekonomi. Selama periode tahun 2015-2019 struktur lapangan usaha sebagian masyarakat Kabupaten Serang telah bergeser dari kelompok lapangan usaha sekunder ke kelompok lapangan usaha tersier yang terlihat dari besarnya kenaikan/penurunan peranan masing-masing kelompok lapangan usaha terhadap pembentukan PDRB Kabupaten Serang.

Sektor pertanian, kehutanan, dan perikanan menempati peringkat keempat dalam kontribusinya terhadap PDRB Kabupaten Serang. Hal tersebut menunjukan bahwa kontribusi sektor pertanian, kehutanan, dan perikanan memberikan kontribusi yang relative besar terhadap PDRB Kabupaten Serang. Kontribusi tersebut berbeda-beda setiap tahunnya, tetapi ada kecenderungan yang semakin menuruun. Tahun 2015-2016 kontribusi sektor pertanian sempat menalami peningkatan yaitu dari $8,9 \%$ menjadi $9,02 \%$; namun tahun-tahun selanjutnya terus menurun hingga tahun 2019 menjadi 8,5\%. Pada tahun 20152019 sektor pertanian Kabupaten Serang bergeser menuju struktur ekonomi sektor tersier. Pergeseran struktur ekonomi ini disebabkan karena kelompok sektor tersier mengalami peningkatan kontribusi terhadap pendapatan regional Kabupaten Serang. (BPS Kabupaten Serang, 2020)

Berdasarkan dasar fakta di atas maka penelitian ini bertujuan untuk menganalisis arah perubahan struktur 
ekonomi serta sektor-sektor yang menjadi sektor unggulan di Kabupaten Serang berdasarkan indikator PDRB.

\section{METODE PENELITIAN}

Penelitian ini dilakukan di Kabupaten Serang menggunakan data publikasi dari Badan Pusat Statistik Kabupaten Serang tahun 2015-2019. Pemilihan tahun dalam penelitian ini disebabkan

PDRB Kabupaten Serang mengalami peningkatan selama periode Tahun 2015-2019, namun kontribusi sektor pertanian, kehutanan, dan perikanan cenderung mengalami penurunan sedangkan kontribusi sektor non pertanian lainnya meningkat.

Jenis penelitian bersifat deskrptif kuantitatif, yaitu penelitian yang menggambarkan data secara sistematis, dan akurat karena data yang ada berdasarkan publikasi resmi, seperti Badan Pusat Statistik Kabupaten Serang. Penelitian menganalisa hubungan sektor unggulan dengan pergeseran struktur perekonomian di Kabupaten Serang.

Teknik pengumpulan data studi ini dilakukan melalui situs Badan Pusat Statistik (2020) dan data lainnya yang relevan dengan penelitian.
Alat analisis yang digunakan dalam studi penelitian yaitu analisis Location Quotient (LQ) dan Shift Share (SS).

a. Analisis Location Quotient (LQ)

Location Quotient (LQ) merupakan suatu teknik analisis yang digunakan untuk melengkapi analisis Shift Share. Secara umum, analisis ini digunakan untuk menentukan sektor basis/pemusatan dan non basis, dengan tujuan untuk melihat keunggulan komparatif suatu daerah dalam menentukan sektor unggulannya.

Analisis Location Quotient (LQ) ini dapat membandingkan tentang besarnya peranan suatu sektor disuatu daerah terhadap besarnya peranan sektor tersebut ditingkat nasional. Perhitungan Location Quotient (LQ) menggunakan rumus: (Tarigan R. , 2010)

$$
L Q=\frac{S_{i} /_{i}}{S / N}=\frac{S_{i}{ }_{S}}{N_{i} /_{N}}
$$

Dimana:

LQ : besarnya kuosien lokasi suatu sektor ekonomi

$\mathrm{S}_{\mathrm{i}} \quad$ : PDRB sektor i pada tingkat Kabupaten

S : PDRB keseluruhan sektor pada tingkat Kabupaten

$\mathrm{N}_{\mathrm{i}}$ : PDRB sektor i pada tingkat Propinsi 
$\mathrm{N}$ : PDRB keseluruhan sektor pada tingkat Propinsi

Beradasarkan rumus diatas, maka ada 3 kemungkinan nilai LQ yang ditemukan, yaitu:

1. Nilai LQ di sektor $\mathrm{i}=1$; artinya laju pertumbuhan sektor i di Kabupaten Serang sama dengan di Provinsi Banten.

2. Nilai LQ di sektor $\mathrm{i}>1$; artinya laju pertumbuhan sektor i di Kabupaten Serang lebih besar dibanding Provinsi Banten atau sektor i merupakan sektor unggulan sekaligus basis ekonomi di Kabupaten Serang.

3. Nilai LQ di sektor $\mathrm{i}<1$; artinya laju pertumbuhan sektor i di Kabupaten Serang lebih kecil dibanding Provinsi Banten atau sektor i bukan merupakan sektor unggulan sekaligus basis ekonomi di Kabupaten Serang.

b. Analisis Shift Share (SS)

Analisis shift share digunakan untuk menganalisis dan mengetahui pergeseran dan peranan perekonomian di daerah. Secara ringkas, analisis shift share dapat dijelaskan bahwa perubahan suatu variabel regional suatu sektor di suatu wilayah dalam kurun waktu tertentu dipengaruhi oleh pertumbuhan nasional, bauran industri, dan keunggulan kompetitif. (Tarigan, 2010)

$$
D_{i j}=N_{i j}+M_{i j}+C_{i j}
$$

Adapun rumus untuk menghitung komponen diatas dapat diuraikan sebagai berikut:

$$
\begin{gathered}
N_{i j}=E_{i j} \times r_{n} \\
M_{i j}=E_{i j}\left(r_{i n}-r_{n}\right) \\
C_{i j}=E_{i j}\left(r_{i j}-r_{i n}\right)
\end{gathered}
$$

Sedangkan masing-masing laju pertumbuhan didefinisikan sebagai berikut:

$$
\begin{gathered}
r_{i j}=\frac{E_{i j}^{*}-E_{i j}}{E_{i j}} \\
r_{i n}=\frac{E_{i n}^{*}-E_{i n}}{E_{i n}} \\
r_{n}=\frac{E_{n}^{*}-E_{n}}{E_{n}}
\end{gathered}
$$

Dimana:

$E_{i j}^{*} \quad:$ PDRB sektor i di wilayah j pada tahun akhir analisis

$E_{i j} \quad$ : PDRB sektor i di wilayah j pada tahun awal analisis

$r_{n} \quad$ : Laju pertumbuhan nasional atau wilayah referensi (wilayah yang lebih tinggi jenjangnya)

$r_{\text {in }}$ : Laju pertumbuhan sektor i wilayah referensi

HASIL DAN PEMBAHASAN

Struktur Perekonomian Kabupaten Serang

Struktur ekonomi daerah satu dengan daerah lain berbeda-beda 


\section{ANALISIS POTENSI SEKTOR UNGGULAN DAN PERGESERAN STRUKTUR PEREKONOMIAN \\ DI KABUPATEN SERANG TAHUN 2015-2019 \\ Faujatul Hasanah, Iwan Setiawan, Trisna Insan Noor, Eka Purna Yudha}

tergantung pada kondisi daerahnya masing-masing. Struktur ekonomi di setiap daerah dapat berubah dari tahun ke tahun tergantung kontribusi sektor tersebut terhadap PDRB daerah. Sumbangan menurut sektor dalam PDRB digunakan sebagai salah satu ukuran dalam perekonomian regional Kabupaten

Serang. Makin besar kontribusi suatu sektor, maka semakin besar peranan dalam perekonomian daerah tersebut. Struktur ekonomi Kabupaten Serang dari tahun ke tahun mengalami perbedaan. Hal tersebut dapat dilihat pada Tabel 1.

Tabel 1. PDRB Kabupaten Serang ADHK 2010 Menurut Lapangan Usaha tahun 2015-2019 (miliar rupiah)

\begin{tabular}{|c|c|c|c|c|c|c|}
\hline No & Lapangan Usaha & 2015 & 2016 & 2017 & $2018^{*}$ & $2019 * *$ \\
\hline 1 & Pertanian, Kehutanan, dan Perikanan & $3.954,27$ & $4.212,10$ & $4.383,50$ & $4.525,73$ & $4.624,91$ \\
\hline 2 & Pertambangan dan Penggalian & 45,71 & 47,96 & 49,96 & 52,53 & 55,44 \\
\hline 3 & Industri Pengolahan & $22.749,51$ & $23.694,59$ & $24.786,47$ & $25.911,72$ & $26.890,41$ \\
\hline 4 & Pengadaan Listrik dan Gas & 209,33 & 229,25 & 252,18 & 250,45 & 253,47 \\
\hline 5 & $\begin{array}{l}\text { Pengadaan Air; Pengelolaan Sampah, } \\
\text { Limbah, dan Daur Ulang }\end{array}$ & 15,28 & 16,30 & 17,67 & 18,32 & 19,33 \\
\hline 6 & Konstruksi & $4.047,14$ & $4.298,08$ & $4.560,61$ & $4.930,29$ & $5.327,18$ \\
\hline 7 & $\begin{array}{l}\text { Perdagangan Besar dan Eceran; } \\
\text { Reparasi Mobil dan Sepeda Motor }\end{array}$ & $4.115,74$ & $4.259,76$ & $4.501,27$ & $4.691,31$ & $5.080,43$ \\
\hline 8 & Transportasi dan Pergudangan & $1.517,59$ & $1.649,83$ & $1.793,41$ & $1.947,53$ & $2.062,52$ \\
\hline 9 & $\begin{array}{l}\text { Penyediaan Akomodasi dan Makan } \\
\text { Minum }\end{array}$ & $1.026,95$ & $1.087,61$ & $1.166,89$ & $1.256,57$ & $1.348,15$ \\
\hline 10 & Informasi dan Komunikasi & 526,00 & 536,87 & 569,14 & 607,07 & 655,55 \\
\hline 11 & Jasa Keuangan dan Asuransi & $1.072,32$ & $1.256,91$ & $1.296,14$ & $1.363,93$ & $1.370,75$ \\
\hline 12 & Real Estat & $2.185,87$ & $2.300,92$ & $2.476,94$ & $2.703,81$ & $2.916,75$ \\
\hline 13 & $\begin{array}{l}\text { Jasa Perusahaan } \\
\text { Administrasi Pemerintahan, }\end{array}$ & 97,39 & 100,92 & 106,18 & 111,09 & 118,97 \\
\hline 14 & $\begin{array}{l}\text { Pertahanan, dan Jaminan Sosial } \\
\text { Wajib }\end{array}$ & 840,63 & 880,56 & 920,36 & 970,52 & $1.057,36$ \\
\hline 15 & Jasa Pendidikan & $1.401,53$ & $1.457,87$ & $1.548,11$ & $1.649,42$ & $1.774,33$ \\
\hline 16 & Jasa Kesehatan dan Kegiatan Sosial & 224,04 & 242,59 & 261,73 & 277,71 & 303,41 \\
\hline 17 & Jasa Lainnya & 425,29 & 443,06 & 474,21 & 506,41 & 545,50 \\
\hline & PDRB & $44.454,59$ & $46.715,18$ & $49.164,77$ & $51.774,41$ & $54.404,46$ \\
\hline
\end{tabular}

Berdasarkan Tabel 1, sektor yang paling dominan memberikan konstribusi terhadap PDRB Kabupaten Serang adalah sektor industri pengolahan. Sedangkan sector pertanian, kehutanan, dan perikanan berada diurutan keempat dalam kontribusinya terhadap PDRB Kabupaten Serang. Nilai PDRB sektor pertanian, kehutanan, dan perikanan mengalami peningkatan setiap tahunnya, namun jika dilihat dari tabel distribusi persentase sector pertanian memberikan nilai persentase yang semakin menurun. Kontribusi masig-masing sector terhadap pertumbuhan PDRB Kabupaten Serang dapat dilihat pada Tabel 2 . 
Tabel 2. Konstribusi PDRB Kabupaten Serang ADHK 2010 Menurut Lapangan Usaha 2015-2019 (persen)

\begin{tabular}{|c|c|c|c|c|c|c|}
\hline No & Sektor Perekonomian & 2015 & 2016 & 2017 & 2018* & $2019 * *$ \\
\hline & Sektor Primer & 9,00 & 9,12 & 9,02 & 8,84 & 8,60 \\
\hline 1 & Pertanian, Kehutanan, dan Perikanan & 8,90 & 9,02 & 8,92 & 8,74 & 8,50 \\
\hline \multirow[t]{2}{*}{2} & Pertambangan dan Penggalian & 0,10 & 0,10 & 0,10 & 0,10 & 0,10 \\
\hline & Sektor Sekunder & 60,78 & 60,45 & 60,24 & 60,09 & 59,72 \\
\hline 3 & Industri Pengolahan & 51,17 & 50,72 & 50,42 & 50,05 & 49,43 \\
\hline 4 & Pengadaan Listrik dan Gas & 0,47 & 0,49 & 0,51 & 0,48 & 0,47 \\
\hline 5 & $\begin{array}{l}\text { Pengadaan Air; Pengelolaan Sampah, } \\
\text { Limbah, dan Daur Ulang }\end{array}$ & 0,03 & 0,03 & 0,04 & 0,04 & 0,04 \\
\hline \multirow[t]{2}{*}{6} & Konstruksi & 9,10 & 9,20 & 9,28 & 9,52 & 9,79 \\
\hline & $\begin{array}{l}\text { Sektor Tersier } \\
\text { Perdagangan Besar dan Eceran; Reparasi }\end{array}$ & 30,22 & 30,43 & 30,74 & 31,07 & 31,68 \\
\hline 7 & Mobil dan Sepeda Motor & 9,26 & 9,12 & 9,16 & 9,06 & 9,34 \\
\hline 8 & Transportasi dan Pergudangan & 3,41 & 3,53 & 3,65 & 3,76 & 3,79 \\
\hline 9 & Penyediaan Akomodasi dan Makan Minum & 2,31 & 2,33 & 2,37 & 2,43 & 2,48 \\
\hline 10 & Informasi dan Komunikasi & 1,18 & 1,15 & 1,16 & 1,17 & 1,20 \\
\hline 11 & Jasa Keuangan dan Asuransi & 2,41 & 2,69 & 2,64 & 2,63 & 2,52 \\
\hline 12 & Real Estat & 4,92 & 4,93 & 5,04 & 5,22 & 5,36 \\
\hline 13 & Jasa Perusahaan & 0,22 & 0,22 & 0,22 & 0,21 & 0,22 \\
\hline 14 & $\begin{array}{l}\text { Administrasi Pemerintahan, Pertahanan, } \\
\text { dan Jaminan Sosial Wajib }\end{array}$ & 1,89 & 1,88 & 1,87 & 1,87 & 1,94 \\
\hline 15 & Jasa Pendidikan & 3,15 & 3,12 & 3,15 & 3,19 & 3,26 \\
\hline 16 & Jasa Kesehatan dan Kegiatan Sosial & 0,50 & 0,52 & 0,53 & 0,54 & 0,56 \\
\hline 17 & Jasa Lainnya & 0,96 & 0,95 & 0,96 & 0,98 & 1,00 \\
\hline & PDRB & $\mathbf{1 0 0 , 0 0}$ & $\mathbf{1 0 0 , 0 0}$ & 100,00 & 100,00 & $\mathbf{1 0 0 , 0 0}$ \\
\hline
\end{tabular}

Keterangan :

*) Angka Perbaikan

**) Angka Sementara

Sumber : BPS Kabupaten Serang Tahun, 2020

Kontribusi setiap sektor terhadap pertumbuhan PDRB Kabupaten Serang menunjukan bahwa pada tahun 20152019 struktur ekonomi Kabupaten Serang bertumpu pada sektor sekunder yaitu sektor industri pengolahan sebesar 49,43\%. Meski demikian, penduduk Kabupaten Serang sebagian besar masih bergantung di sektor primer, terutama pertanian. Hal tersebut terlihat dari penggunaan lahan pertanian di Kabupaten Serang sampai tahun 2019 sebesar 70,15\% dari luas total wilayah Kabupaten Serang. Dengan persentase penggunaan lahan pertanian yang begitu luas maka dapat dikatakan Kabupaten Serang merupakan daerah yang menonjol kegiatan pertaniannya. Di Propinsi Banten, Kabupaten Serang merupakan daerah pertanian terbesar ketiga setelah Kabupaten Pandeglang dan Kabupaten Lebak.

Sementara pada tahun 2015-2019 sektor pertanian Kabupaten Serang bergeser menuju struktur ekonomi sektor tersier menjadi 31,68\% pada tahun 2019 . Pergeseran struktur ekonomi ini disebabkan karena kelompok sektor 
tersier mengalami peningkatan kontribusi terhadap pendapatan regional Kabupaten Serang. Distribusi PDRB Kabupaten Serang menunjukan bahwa sektor pertanian memiliki peranan/sumbangan yang cukup besar dalam perekonomian Kabupaten Serang yaitu di urutan ke empat seebsar 8,5 persen tahun 2019, meskipun sektor pertanian memiliki peranan yang cukup besar namun kontribusi sektor pertanian dari tahun 2016 hingga 2019 mengalami perlambatan. Sektor terbesar kedua dalam perekonomian Kabupaten Serang adalah sektor konstruksi sebesar 9,79 persen tahun 2019 dan mengalami peningkatan dari tahun 2015-2019.

\section{Analisis Sektor Unggulan Kabupaten}

\section{Serang (Location Quotient)}

Berdasarkan nilai rata-rata $\mathrm{LQ}$ sektor-sektor ekonomi di Kabupaten Serang selama periode 2015-2019, terdapat empat sektor yang berkedudukan kuat sebagai sektor basis ekonomi wilayah dengan nilai LQ lebih besar dari satu, yaitu sektor pertanian, kehutanan, dan perikanan; sektor industri pengolahan; sektor administrasi pemerintahan, pertahanan, dan jaminana sosial wajib; serta sektor jasa pendidikan. Hal ini menunjukkan bahwa keempat sektor tersebut memiliki keunggulan nilai kontribusi dalam perbandingan antar wilayah dan merupakan sektor yang berperan dalam perekonomian wilayah Kabupaten Serang, serta layak untuk dikembangkan. Hasil perhitungan nilai LQ sektor ekonomi di Kabupaten Serang tahun 2015-2019 dapat dilihat pada Tabel 3.

Sektor pertanian, kehutanan, dan perikanan memiliki rata-rata nilai LQ paling besar dan lebih dari satu. Berdasarkan hasil analisis pada Tabel 3, nilai LQ sektor pertanian, kehutanan, dan perikanan di Kabupaten Serang merupakan sektor yang menjadi unggulan atau sektor basis karena memiliki ratarata nilai LQ sebesar 1,59. Nilai tersebut berarti 1 bagian digunakan untuk kebutuhan konsumsi daerah sendiri, sedangkan sisanya 0,59 untuk ekspor ke daerah lain. Hal ini menunjukkan bahwa peranan sektor pertanian bagi perekonomian Kabupaten Serang relatif besar. Luas wilayah Kabupaten Serang yang didominasi oleh lahan pertanian merupakan suatu potensi yang cukup baik bagi berkembangnya sektor pertanian. Lokasi yang strategis dengan daerahdaerah yang memiliki tingkat pertumbuhan yang tinggi, seperti Kabupaten Tangerang, Kota Tangerang, 
serta adanya akses jalan tol menuju Pelabuhan Merak, dapat mempermudah aksesbilitas pemasaran produk pertanian. Menurut Amrullah (2010) secara umum ada tiga subsektor pertanian yang memberikan kontribusi terhadap PDRB sektor pertanian Kabupaten Serang. Ketiganya adalah subsektor tanaman bahan makanan, subsektor peternakan dan subsektor perikanan. Potensi yang besar ini hingga kini terus didukung oleh Pemerintah Daerah Kabupaten Serang melalui berbagai upaya, terutama pengembangan agribisnis, agar semakin meningkatkan kesejahteraan petani, peternak maupun nelayan.

Keunggulan sektor pertanian, kehutanan, dan perikanan dapat terlihat dari hasil sektor ini di Kabupaten Serang. Tanaman pangan di Kabupaten Serang meliputi padi, palawija, sayur-sayuran dan buah-buahan. Berdasarkan data Badan Pusat Statistik Kabupaten Serang (2019), produksi padi di Kabupaten Serang mencapai 512.943 ton dengan luas panen sebesar 93.604 ha, untuk tanaman palawija, ubi kayu memiliki produktivitas tertinggi yaitu sebesar 258,63 ku/ha sedangkan kacang kedelai memiliki produktivitas sebesar 9,04 ku/ha. Di Kabupaten Serang beberapa tanaman perkebunan mempunyai lahan yang cukup luas diatas 1.000 ha antara lain kelapa, kopi, cengkeh dan kakao. Potensi peternakan di Kabupaten Serang terdiri dari ternak besar (sapi perah, sapi potong, kerbau, dan kuda) dan ternak kecil (kambing, domba), untuk ungags meliputi ayam buras, ayam ras pedaging, ayam ras petelur, dan itik. Sedangkan untuk potensi perikanan di Kabupaten Serang sebagian besar di dorong oleh tingginya hasil perikanan budidaya yaitu sebesar 71.297,18 ton, sedangkan perikanan tangkap sebesar $9.864,43$ ton. Potensi perikanan ini didorong dengan adanya wilayah pesisir Kabupaten Serang yaitu pantai Barat dan pantai Utara. Di pantai Barat terdapat 2 kecamatan yaitu Kecamatan Anyar dan Cinangka, sementara dibagian utara terdapat Kecamatan Pulo Ampel, Bojonegara, Kramatwatu, Pontang, Tirtayasa dan Tanara. Sementara jika di lihat dari arahan RTRW Kabupaten Serang maka telah ditetapkan adanya SWK (Sub Wilayah Kota) Tirtayasa dengan pengembangan fungsi utama sebagai pusat pengembangan perikanan tambak serta pertanian tanaman pangan lahan basah dan kering dengan pusat pengembangan di Kecamatan Pontang. 
Tabel 3. Rata-rata Nilai LQ Sektor Ekonomi di Kabupaten Serang Tahun 2015-2019 Atas Harga Konstan Tahun 2010

\begin{tabular}{|c|c|c|c|c|c|c|c|c|}
\hline No & Lapangan Usaha & 2015 & 2016 & 2017 & 2018 & 2019 & $\begin{array}{l}\text { Rata- } \\
\text { rata }\end{array}$ & Peringkat \\
\hline \multirow{2}{*}{1} & Pertanian, Kehutanan, dan & & & & & & & \\
\hline & Perikanan & 1,58 & 1,58 & 1,59 & 1,59 & 1,60 & 1,59 & 1 \\
\hline 2 & Pertambangan dan Penggalian & 0,14 & 0,14 & 0,15 & 0,15 & 0,16 & 0,15 & 17 \\
\hline 3 & Industri Pengolahan & 1,40 & 1,41 & 1,43 & 1,45 & 1,46 & 1,43 & 2 \\
\hline \multirow[t]{2}{*}{4} & Pengadaan Listrik dan Gas & 0,40 & 0,46 & 0,50 & 0,47 & 0,49 & 0,46 & 12 \\
\hline & Pengadaan Air; Pengelolaan & & & & & & & \\
\hline \multirow[t]{2}{*}{5} & Sampah, Limbah, dan Daur & & & & & & & \\
\hline & Ulang & 0,37 & 0,37 & 0,37 & 0,37 & 0,37 & 0,37 & 14 \\
\hline \multirow[t]{2}{*}{6} & Konstruksi & 0,98 & 0,98 & 0,97 & 0,98 & 0,97 & 0,98 & 6 \\
\hline & Perdagangan Besar dan Eceran; & & & & & & & \\
\hline \multirow[t]{2}{*}{7} & Reparasi Mobil dan Sepeda & & & & & & & \\
\hline & Motor & 0,69 & 0,69 & 0,69 & 0,67 & 0,68 & 0,68 & 8 \\
\hline 8 & Transportasi dan Pergudangan & 0,54 & 0,54 & 0,55 & 0,56 & 0,59 & 0,56 & 11 \\
\hline \multirow{2}{*}{9} & Penyediaan Akomodasi dan & & & & & & & \\
\hline & Makan Minum & 1,00 & 0,99 & 0,98 & 0,99 & 0,99 & 0,99 & 5 \\
\hline 10 & Informasi dan Komunikasi & 0,22 & 0,21 & 0,20 & 0,20 & 0,20 & 0,21 & 16 \\
\hline 11 & Jasa Keuangan dan Asuransi & 0,88 & 0,90 & 0,90 & 0,89 & 0,87 & 0,89 & 7 \\
\hline 12 & Real Estat & 0,61 & 0,60 & 0,60 & 0,61 & 0,61 & 0,60 & 10 \\
\hline \multirow[t]{2}{*}{13} & Jasa Perusahaan & 0,22 & 0,22 & 0,21 & 0,21 & 0,21 & 0,21 & 15 \\
\hline & Administrasi Pemerintahan, & & & & & & & \\
\hline \multirow[t]{2}{*}{14} & Pertahanan, dan Jaminan Sosial & & & & & & & \\
\hline & Wajib & 1,09 & 1,07 & 1,08 & 1,08 & 1,10 & 1,08 & 3 \\
\hline 15 & Jasa Pendidikan & 1,09 & 1,07 & 1,06 & 1,06 & 1,06 & 1,07 & 4 \\
\hline \multirow{2}{*}{16} & Jasa Kesehatan dan Kegiatan & & & & & & & \\
\hline & Sosial & 0,44 & 0,44 & 0,44 & 0,44 & 0,45 & 0,44 & 13 \\
\hline 17 & Jasa Lainnya & 0,68 & 0,66 & 0,65 & 0,65 & 0,65 & 0,66 & 9 \\
\hline
\end{tabular}

Sumber:Hasil Perhitungan, 2020

Tabel 3 juga menunjukan bahwa sebagian sektor ekonomi di Kabupaten Serang memiliki rata-rata nilai kurang dari satu. Hal ini menunjukan bahwa peranan sektor-sektor tersebut bagi perekonomian Kabupaten Serang relatif kecil dan masih tergantung pada daerah lain untuk memenuhi permintaan akan sektor-sektor tersebut

Penelitian yang dilakukan oleh Yudha \& Dina (2020) mengenai potensi wilayah di kawasan perbatasan Indonesia yaitu Kabupaten Natuna, menyatakan bahwa sektor pertanian, kehutanan, dan perikanan juga menjadi sektor unggulan di wilayah tersebut. Namun berbeda dengan Kabupaten Serang, keunggulan di Kabupaten Natuna ini sebagian besar di dorong oleh tingginya hasil perikanan tangkap. Untuk mendukung pengembangan komoditas perikanan tangkap, Pemerintah setempat membangun Sentra Kelautan dan Perikanan Terpadu (SKPT) yang berada di Selat Lampa. KPT Natuna menjadi bagian dari pengembangan SKPT di 
berbagai daerah perbatasan dan pulaupulau terluar di Indonesia, yang memiliki berbagai berbagai fungsi, dari mulai ekonomi-sosial hingga fungsi kedaulatan negara.

\section{Analisis Perubahan Struktur Ekonomi}

\section{Kabupaten Serang (Shift Share)}

Potensi pertumbuhan ekonomi per sektor dapat dianalisis dengan menggunakan metode shift share analysis, dengan fungsi dari regional share, proportional shift, dan differential shift.. Analisis ini dilakukan dengan membandingkannya terhadap perekonomian Provinsi Banten. Hasil analisis shift-share Kabupaten Serang dapat dilihat pada Tabel 4.

Berdasarkan hasil analisis shift share, pertumbuhan sektor pertanian, kehutanan, dan kehutanan berada di urutan ke empat di Kabupaten Serang dalam pertumbuhan rata-rata Provinsi Banten. Sektor pertanian, kehutanan, dan perikanan memiliki angka komponen regional share yang bernilai positif. Hal ini menunjukan bahwa sektor pertanian, kehutanan, dan perikanan di Kabupaten Serang mempunyai efek positif dalam mendiring pertumbuhan PDRB sektor yang sama di Provinsi Banten yaitu sebesar 962,28.

Tabel 4. Hasil Analisis Shift-Share Kabupaten Serang Tahun 2015-2019

\begin{tabular}{|c|c|c|c|c|c|}
\hline & \multirow[b]{2}{*}{ Lapangan Usaha } & \multicolumn{3}{|c|}{ Komponen Shift } & \multirow[b]{2}{*}{ Pertumbuhan } \\
\hline & & $\begin{array}{l}\text { Regional } \\
\text { Share }\end{array}$ & $\begin{array}{l}\text { Propotional } \\
\text { Shift }\end{array}$ & $\begin{array}{l}\text { Differential } \\
\text { Shift }\end{array}$ & \\
\hline 1 & Pertanian, Kehutanan, dan Perikanan & 962,28 & $-263,66$ & $-27,98$ & 670,64 \\
\hline 2 & Pertambangan dan Penggalian & 11,12 & $-9,36$ & 7,96 & 9,73 \\
\hline 3 & Industri Pengolahan & $5.536,15$ & $-2.167,75$ & 772,50 & $4.140,90$ \\
\hline 4 & Pengadaan Listrik dan Gas & 50,94 & $-51,46$ & 44,66 & 44,14 \\
\hline 5 & $\begin{array}{l}\text { Pengadaan Air; Pengelolaan Sampah, } \\
\text { Limbah, dan Daur Ulang }\end{array}$ & 3,72 & 0,40 & $-0,07$ & 4,05 \\
\hline 6 & Konstruksi & 984,88 & 437,69 & $-142,53$ & $1.280,04$ \\
\hline 7 & $\begin{array}{l}\text { Perdagangan Besar dan Eceran; } \\
\text { Reparasi Mobil dan Sepeda Motor }\end{array}$ & $1.001,58$ & 117,84 & $-154,72$ & 964,69 \\
\hline 8 & Transportasi dan Pergudangan & 369,31 & 32,52 & 143,11 & 544,93 \\
\hline 9 & $\begin{array}{l}\text { Penyediaan Akomodasi dan Makan } \\
\text { Minum }\end{array}$ & 249,91 & 110,70 & $-39,41$ & 321,20 \\
\hline 10 & Informasi dan Komunikasi & 128,00 & 70,39 & $-68,84$ & 129,55 \\
\hline 11 & Jasa Keuangan dan Asuransi & 260,95 & 62,40 & $-24,93$ & 298,43 \\
\hline 12 & Real Estat & 531,94 & 265,74 & $-66,79$ & 730,88 \\
\hline 13 & Jasa Perusahaan & 23,70 & 9,60 & $-11,72$ & 21,58 \\
\hline 14 & $\begin{array}{l}\text { Administrasi Pemerintahan, } \\
\text { Pertahanan, dan Jaminan Sosial Wajib }\end{array}$ & 204,57 & 26,35 & $-14,19$ & 216,73 \\
\hline 15 & Jasa Pendidikan & 341,07 & 114,95 & $-83,22$ & 372,80 \\
\hline 16 & Jasa Kesehatan dan Kegiatan Sosial & 54,52 & 23,34 & 1,51 & 79,37 \\
\hline 17 & Jasa Lainnya & 103,50 & 50,29 & $-33,57$ & 120,21 \\
\hline & PDRB & $10.818,14$ & $-1.170,02$ & 301,75 & $9.949,87$ \\
\hline
\end{tabular}

Sumber:Hasil Perhitungan, 2020 


\section{ANALISIS POTENSI SEKTOR UNGGULAN DAN PERGESERAN STRUKTUR PEREKONOMIAN \\ DI KABUPATEN SERANG TAHUN 2015-2019 \\ Faujatul Hasanah, Iwan Setiawan, Trisna Insan Noor, Eka Purna Yudha}

Sementara itu sektor yang memiliki regional share paling cepat adalah sektor industri pengolahan sebesar 5.536,15. Sedangkan sektor yang memiliki regional share paling lambat adalah sektor pengadaan air; pengelolaan sampah, limbah, dan daur ulang sebesar 3,72. Berdasarkan hasil regional share, dapat dikatakan bahwa untuk meningkatkan pertumbuhan ekonomi regional Kabupaten Serang yang lebih tinggi adalah dengan mendorong sektor-sektor yang memiliki pertumbuhan regional yang tinggi, salah satunya sektor pertanian, kehutanan, dan perikanan.

Sektor pertanian, kehutanan, dan perikanan merupakan salah satu sektor yang pertumbuhannya cukup tinggi di Kabupaten Serang, yaitu berada pada urutan keempat. Namun berdasarkan hasil shift share analysis pada Tabel 4, sektor pertanian, kehutanan, dan perikanan bukan merupakan sektor yang maju. Hal tersebut dapat terlihat dari nilai komponen propotional shift yang bernilai negatif yaitu sebesar $-263,66$. Pengukuran propotional shift ini memungkinkan untuk mengetahui apakah perekonomian daerah terkonsentrasi pada indutri-industri yang tumbuh lebih cepat ketimbang perekonomian yang dijadikan referensi (Yudha \& Dina, 2020). Hasil propotional shift menunjukan lima besar sektor yang memiliki nilai paling tinggi adalah sektor konstruksi; sektor real estate; serta sektor perdagangan besar dan eceran, reparasi mobil dan sepeda motor. Sedangkan sektor pertanian, kehutanan, dan perikanan; sektor pertambangan dan penggalian; sektor industri pengolahan; serta sektor pengadaan listrik dan gas di Kabupaten Serang memiliki nilai propotional shift negative, artinya sektorsekrot tersebut tumbuh lebih lambat dibandingkan sektor yang sama di tingkat Provinsi Banten.

Hasil shift share analysis menunjukan bahwa sektor ekonomi di Kabupaten Serang yang memiliki daya saing tinggi adalah industri pengolahan, hal ini tercermin dari nilai komponen differential shift yang bernilai positif yaitu sebesar 772,50. Differential shift yang memberikan informasi dalam menentukan seberapa jauh daya saing industri daerah (lokal) dengan perekonomian yang dijadikan referensi. Jika pergeseran diferensial dari suatu industri adalah posisitf, maka industri tersebut relatif lebih tinggi daya saingnya dibandingkan industri yang sama pada perekonomian yang dijadikan referensi (Yudha \& Dina, 2020). Sementara itu sektor pertanian, kehutanan dan 
perikanan memiliki kompenen differential shift yang bernilai negative yaitu sebesar $-27,98$. Hal ini menunjukan bahwa sektor sektor pertanian, kehutanan dan perikanan tersebut memiliki daya saing yang rendah atau kurang mampu bersaing dengan produk sektor sejenis dari wilayah lain yang masuk ke Kabupaten Serang.

\section{KESIMPULAN DAN SARAN}

Berdasar hasil penjelasan pada uraian sebelumnya, dapat disimpulkan bahwa kontribusi sektor perekonomian terhadap PDRB ADHK Kabupaten Serang tahun 2015-2019 terbesar terdapat pada sektor industri pengolahan, sedangkan sektor pertanian, kehutanan, dan perikanan menempati urutan keempat Distribusi persentase sektor pertanian memberikan nilai persentase yang semakin menurun dan bergeser menuju sektor tersier, hal ini terlihat dari semakin meningkatnya sektor tersier terutama sektor konstruksi. Hasil perhitungan nilai rata-rata LQ sektor-sektor ekonomi di Kabupaten Serang selama periode 20152019 terdapat empat sektor yang berkedudukan kuat sebagai sektor basis ekonomi wilayah, yaitu sektor pertanian, kehutanan, dan perikanan; sektor industry pengolahan; sektor administrasi pemerintahan, pertahanan, dan jaminana sosial wajib; serta sektor jasa pendidikan. Analisis shift share menunjukan pada tahun 2015-2019 terdapat empat sektor yang memiliki nilai propotional shift negative yaitu sektor pertanian, kehutanan, dan perikanan; sektor pertambangan dan penggalain; sektor industri pengolahan; serta sektor pengadaan listrik dan gas, hal ini menunjukan bahwa sektor-sektor tersebut tumbuh lebih lambat dibandingkan sektor yang sama ditingkat Provinsi Banten. Sedangkan sektor yang memiliki daya saing tinggi di Kabupaten Serang adalah sektor industry pengolahan; sektor transportasi dan pergudangan; sektor pengadaan listrik dan gas; sektor pertambangan dan penggalian; serta jasa kesehatan dan kegiatan sosial, hal ini tercermin dari nilai komponen differential shift yang bernilai positif.

\section{DAFTAR PUSTAKA}

Amrullah, H. (2010). Kontribusi Sektor Pertanian dalam Pembangunan Wilayah Kabupaten Serang dengan Pendekatan Analisis Location Quotient dan Shift Share. Surakarta: Tesis. Universitas Sebelas Maret.

Arsyad, L. (2010). Pengantar Perencanaan dan Pembangunan Ekonomi. Yogyakarta: BPFE.

Badan Pusat Statistik Kabupaten Serang. (2019). Kabupaten Serang dalam 
Angka 2019. Serang: Badan Pusat Statistik Kabupaten Serang.

Badan Pusat Statistik Kabupaten Serang. (2020). Produk Domestik Regional Bruto

Kabupaten Serang Menurut Lapangan Usaha 2015-2019. Serang: Badan Pusat Statistik Kabupaten Serang.

Badan Pusat Statistik Provinsi Banten. (2020). Produk Domestik Regional Bruto Provinsi

Banten Menurut Lapangan Usaha 2015 2019. Serang: Badan Pusat Statistik Provinsi Banten

Faried, A. I., \& Sembiring, R. (2019). Perekonomian Indonesia: Antara Konsep dan Realita Keberlanjutan Pembangunan. Medan: Yayasan Kita Menulis.
Subandi. (2014). Ekonomi Pembangunan. Bandung: Alfabeta.

Tarigan, R. (2010). Ekonomi Regional: Teori dan Aplikasi. Jakarta: Bumi Aksara.

Tarigan, R. (2010). Perencanaan Pembangunan Wilayah Edisi Revisi. Jakarta: Bumi Aksara.

Todaro, M. P., Smith, \& C, S. (2011). Pembangunan Ekonomi Edisi Kesembilan. Jakarta: Erlangga.

Yudha, E. P., \& Dina, R. A. (2020). Pengembangan Potensi Wilayah Kawasan Perbatasan Negara Indonesia (Studi Kasus: RanaiNatuna). Tata Loka Volume 22 Nomor 3, 366-378 